\title{
Stability Monomolecular Properties of Archaeal Tetraether Lipids Layers onto Solid Substrates
}

\author{
Sri Vidawati1, Udo Bakowsky² \\ ${ }^{1}$ Faculty of Post Graduate Engineering, National Institute of Science and Technology, Jakarta, Indonesia \\ ${ }^{2}$ Department of Pharmaceutics and Biopharmaceutics, Philipps University Marburg, Marburg, Germany \\ Email: udo.bakowsky@staff.uni-marburg.de, sri.vidawati@istn.ac.id
}

How to cite this paper: Vidawati, S. and Bakowsky, U. (2022) Stability Monomolecular Properties of Archaeal Tetraether Lipids Layers onto Solid Substrates. Advances in Biological Chemistry, 12, 29-37. https://doi.org/10.4236/abc.2022.121003

Received: December 27, 2021

Accepted: February 22, 2022

Published: February 25, 2022

Copyright ( 2022 by author(s) and Scientific Research Publishing Inc. This work is licensed under the Creative Commons Attribution International License (CC BY 4.0).

http://creativecommons.org/licenses/by/4.0/

\begin{abstract}
This paper reports the recent findings related to the stability properties of tetraether lipid layers. Organizations moleculars of chemical structure modified of Langmuir-Blodgett layers of archael tetraether lipids from the archebacterium Sulfolobus acidocaldarius on the wafer silicon substrates are investigated stable and organized. The behavior of Langmuir-Blodgett layers of chemical structure modified of archaeal tetraether lipids on the wafer silicon substrates is characterization using Differential Scanning Calorimetry (DSC) and Atomic Force Microscopy (AFM). The thermodynamics behavior and stability of Langmuir-Blodgett layers of archael tetraether lipids on the wafer silicon substrates are shown. Stability of the lipid membranes is of great importance to a number of biomedical applications, including intravenous drug delivery, biomaterials, and biosensors.
\end{abstract}

\section{Keywords}

Archaeal Tetraether Lipids, Langmuir-Blodgett Layers, Lipid Organizations

\section{Introduction}

Lipid membranes supported on solid substrates are considered as an important model to mimic the natural cell membranes in fundamental studies [1]. Supported lipid mono- and bilayers represent one of the most promising classes of model membranes [2] [3]. Lipid membranes have risen to prominence as an important tool for biologists and bioengineers investigating membrane phenomena. The capabilities of supported lipid membranes have opened the door to biotechnology applications in medicine, diagnostics, sensor systems, environmental monitoring and energy storage [4]. 
GDNT

Caldarchaeol- $-\mathrm{PO}_{4}$

Archaeal tetraether lipids membranes could be of great value in the field of biomedicine including intravenous drug delivery [5], biotechnology [6], biosensors [7] and membrane implant [8] because these bolaamphiphilic tetraether lipids are the main compound in membranes of archaea into ordered structures with extraordinarily stability against chemical and microbial degradation under extreme environmental conditions such as temperatures, $\mathrm{pH}$, high hydrostatic pressure, and high salt concentrations [9] [10]. Gliozzi et al. [11] were displayed that neutral tetraetherlipids from the archebacterium Sulfolobus acidocaldarius form stable black lipid membranes which appeared to be organized as monolayers. Vidawati et al. [12] [13] [14] were shown that stability organization molecular of Langmuir-Blodgett films chemically modified structure of archaeal tetraetherlipids. Archaeal tetraetherlipids from the archaebacterium Sulfolobus acidocaldarius formed a monomolecular lipid layer with upright standing molecules at film consistent thicknesses of approximately $5 \mathrm{~nm}$ determined by ellipsometry and atomic force microscopy.

In this paper, we have preparation of the chemically modified archaeal tetraether lipids in Figure 1. The membrane lipids on the wafer silicon substrate

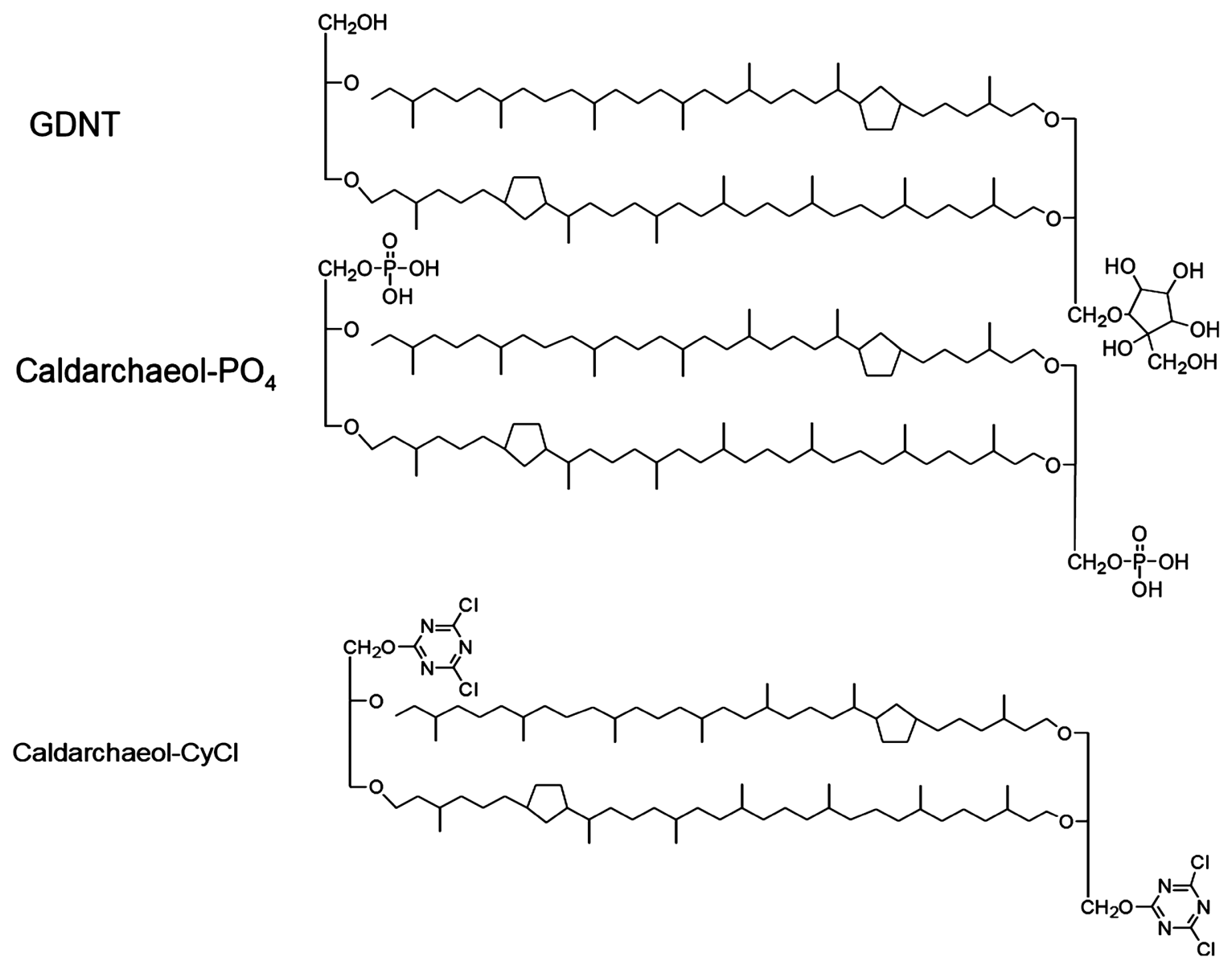

Figure 1. Chemical structure of the archaebacterial tetraether lipids: GDNT, caldarchaeol- $\mathrm{PO}_{4}$, and caldarchaeol-CyCl.

were prepared by Langmuir-Blodgett method. Chemically modified structures 
of archaeal tetraether lipids: GDNT, caldarchaeol- $\mathrm{PO}_{4}$, and caldarchaeol-CyCl represent model lipids at high surface pressure [12] [13]. It could be shown that in the monomolecular Langmuir-Blodgett film of chemically modified structure of archaeal tetraether lipids at the air-water interface molecules on the wafer silicon substrate is oriented upright standing and the horseshoe-like orientation [15] [16].

This paper reports the recent findings related to the behaviour and the stability of chemical modified structure of Langmuir-Blodgett film tetraether lipid at the air-water interfaces on the wafer silicon substrates, with special attention to the calorimetry studies which would be in line with the assumption that the archael tetraether lipids membrane has significant influence on lipid conformation, membrane thickness organization, and headgroup orientation.

\section{Material and Methods}

\subsection{Lipid and Other Materials}

Lipids from archae Sulfolobus Acidocaldarius is used for all of these experiments. A two-step chromatography method was developed, using DEAE-cellulose and silica columns, and the samples were eluted with chloroform and methanol. The head-groups (hydroxyl groups) of caldarchaeol are synthesized with $\mathrm{PO}_{4}$ in accordance with the method Bakowsky et al. [17]. The experiments were conducted with the tetraether lipids of the highest purity available. All other chemicals obtained from Merck (Damstadt) or Sigma (Deisenhofen) at the highest purity.

\subsection{Silicon Wafers Subtrates}

The wafer silicon cut into dimensions $1.0 \mathrm{~cm} \times 1.0 \mathrm{~cm}$. We use the Piranha method to clean the wafer silicon substrates for all experiments. The Piranha solution, which is a mixture of concentrated sulfuric acid and hydrogen peroxide ( $7: 3$ concentrated $\mathrm{H}_{2} \mathrm{SO}_{4}: \mathrm{H}_{2} \mathrm{O}_{2}$ ), is a very common oxidizing agent used to clean silicon wafers substrate.

\subsection{Langmuir Blodgett Monolayer Experiments}

The investigations of the monolayer Langmuir is excreted by the commercial film balance ( $\mathrm{R} \& \mathrm{~K} \mathrm{GmbH}$, Mainz, Germany) by going a rectangular thermostatted Teflon trough (area $418 \mathrm{~cm}^{2}, 1 \mathrm{~cm}$ depth). The surface pressure is measured with a filter paper Wilhelmy balance. For the film balance experiments the tetraether lipids dissolved in chloroform/methanol 2:1 (v:v) consisting of a concentration $1.0 \mathrm{mmol} / \mathrm{l}$. Pure water of Milli Q quality (18.2 M, pH 5.6) was used as a subphase. All experiments were conducted at a temperature of $19^{\circ} \mathrm{C} \pm 11^{\circ} \mathrm{C}$. After spreading, the lipid films were equilibrated at zero surface pressure before starting the measurements. All films were compressed at a constant speed of $0.045 \mathrm{~cm}^{2} \cdot \mathrm{s}^{-1}\left(2.5 \times 10^{-2} \mathrm{~nm}^{2} \cdot \mathrm{s}^{-1}\right.$ per molecule $)$. 


\subsection{Atomic Force Microscopy Measurements}

The surface morphology of the Langmur-Blodgett film was characterized using Atomic force microscopy. Atomic force microscopy was effected using a NanoWizard apparatus (JPK instruments, Berlin, Germany) under atmospheric state. Commercial pyramidal $\mathrm{Si}_{3} \mathrm{~N}_{4}$ tips (NSC16AlBS, Micromasch, Estonia) mounted on a cantilever with a length of $230 \mu \mathrm{m}$, a resonance frequency of around 170 $\mathrm{kHz}$ and a nominal force constant of around $40 \mathrm{~N} / \mathrm{m}$ were used. The measurements were effected intermittently to defend sample destruction. The scan size and scan frequency were applying from 0.5 to $1.5 \mathrm{~Hz}$. AFM image result was effected by display the signal height in the retrace direction $(512 \times 512$ pixels $)$.

\subsection{Differential Scanning Calorimetry (DSC)}

Differential scanning calorimetry (DSC) is one of the thermo-analytical techniques. The calorimeter measures heat into or out of the sample. Differential calorimeter measures the heat of sample relative to reference. A differential scanning calorimeter does all of the above and heats the sample with a linear temperature ramp. DSC is a technique in which the difference in the amount of heat required to increase the sample temperature and reference are measured as a temperature function. DSC is the most commonly used method of thermal analysis, mainly due to its speed, simplicity, and availability.

Differential scanning calorimetry (DSC) is the primary technique for measuring energetics thermally induced phase transitions and conformational changes, which makes DSC especially equipment for investigating the thermodynamic properties of lipid/protein interactions.

DSC measures the heat flowing through sample undergoing physical transformation such as structural change or phase transition, compared to reference material, when heated or cooled at identical, and pre-defined levels. Due to the absorption (or release) of heat from the sample during the thermal transition, a temperature differential $(\Delta \mathrm{T})$ develops between the sample and reference cells. The instrumental control system minimizes the temperature differential by supplying more (or less) heat to the sample cell to maintain its temperature equal to the reference cell. The thermal power need to maintain both cells at the same temperature is recorded and altered in heat output heatcapacity versus temperature. DSC equipment is used to describe heat transitions from organic and inorganic materials. DSC has the ability to characterize heat capacity $(\mathrm{Cp})$, transition temperature $(\mathrm{Tg})$ quickly and accurately. The accurately of the measurement results depends on the calibration of the material especially at the transition temperature.

For this experiment the heat capacity of chemical modified stucture of tetraether lipid monolayers at the air-water interfaces on the wafer silicon substrates is measured using DSC-Shimadzu-50 equipment. In this characterization measurements range from $28^{\circ} \mathrm{C}$ to $100^{\circ} \mathrm{C}$ at velocity of $5.0^{\circ} \mathrm{C} / \mathrm{min}$ under the nitrogen atmosphere. 


\section{Result and Discussion}

Formation and stability of monomolecular monolayers from chemical modified structure of tetraether lipid GDNT, caldarchaeol-PO4, caldarchaeol-CyCl have been investigated. Long term stability of the tetraether lipids film can be derived from Figure 2, at $19^{\circ} \mathrm{C}, \mathrm{pH} 5.5$ compression-decompression surface pressure/area isotherms for caldarchaeol-CyCl, GDNT, caldarchaeol- $\mathrm{PO}_{4}$. The behaviors of Langmuir film of GDNT, caldarchaeol- $\mathrm{PO}_{4}$, caldarchaeol-CyCl are performed thermodynamic stable according Vidawati et al. [12].

The isothermal surface is generally used to characterize the strength and stability of LB-films. The compression-decompression hysteresis cycles of GDNT, caldarchaeol- $\mathrm{PO}_{4}$, caldarchaeol-CyCl are performed and resulting compression-decompression curves showing the thermodynamic stability of the tetraether lipids [13] [14].

Main phospholipid (MPL) is essentially anionic, the high stability of the MPL film may appear surprising. Apparently, the stabilizing forces, consisting of hydrophobic interactions between the long hydrocarbon chains in the apolar core of the layer and, possibly, hydrogen bonds between glycosidic head groups in the polar region, are strong enough to overcome the destabilizing repulsive forces between the charged head groups. This is supported by differential scanning calorimetry data showing that the thermal properties of hydrated tetraether lipids are almost completely independent of $\mathrm{pH}$.

Based on Figure 2, the molecular area of the asymmetric GDNT has a collapse film pressure of $28 \mathrm{mN} / \mathrm{m}$ and a molecular area between $1.2 \mathrm{~nm}^{2}$ until $1.7 \mathrm{~nm}^{2}$. These findings are reported that GDNT molecules are organised in an upright standing configuration with a molecular area of $0.82 \mathrm{~nm}^{2}$ in monomolecular films, in monolayer experiments with GDNT from $S$. acidocaldarius. The symmetric caldarchaeol- $\mathrm{PO}_{4}$ had a collapse pressure of $18 \mathrm{mN} / \mathrm{m}$ and a molecular area between 1.0 and $1.5 \mathrm{~nm}^{2}$ [12] [14].

The caldarchaeol-CyCl molecules are organised in an upright standing configuration [12]. This finding is compatible with the assumption that, under these experimental conditions, only one of the two polar headgroups of MPL is anchored in

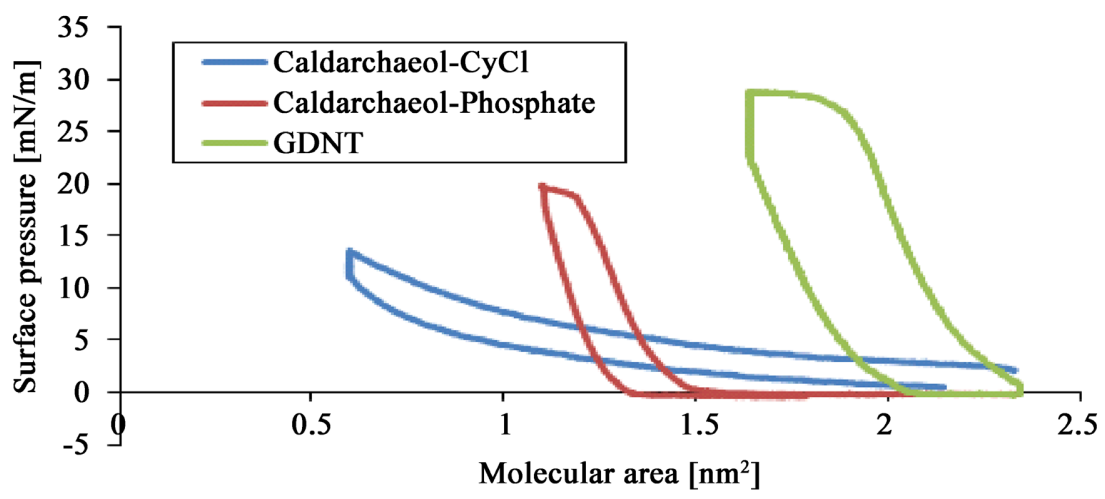

Figure 2. The compression-decompression hysteresis cycles surface pressure/area isotherms for caldarchaeol-CyCl, GDNT, caldarchaeol- $\mathrm{PO}_{4}[12]$. 
the subphase, i.e. the single molecules in the monofilm must be oriented upright. The data do not allow concluding whether the orientation of the asymmetric molecules is uniform or not, i.e. whether the direction is parallel or antiparallel.

AFM is exploited for studying and analyzing the surface morphology of the Langmuir-Blodgett films of GDNT, caldarchaeol- $\mathrm{PO}_{4}$, and caldarchaeol-CyCl on the silicon wafer substrate. The AFM images by high retrace 3 dimensional image of Langmuir-Blodgett films of GDNT, caldarchaeol- $\mathrm{PO}_{4}$, and caldarchaeol- $\mathrm{CyCl}$ showed in Figures 3(a)-(c). The AFM phenomenon described a comparatively homogeneous lipid layer which resembles a collection of some small flat islands and some domains. These results from AFM characterization suggest that the organization molecular of Langmuir-Blodgett films of GDNT, caldarchaeol- $\mathrm{PO}_{4}$, and caldarchaeol-CyCl was stable and organized [12] [13] [15].

Differential Scanning Calorimetry (DSC) is an established measurement method used at scale in various areas of research, development, and quality inspection and testing. During a large temperature range, thermal effects can be quickly identified and the relevant temperature and the characteristic caloric values are determined using substance quantities in the $\mathrm{mg}$ range. Measurement values obtained by DSC allow heat capacity, heat transition, and glass transition to be determined. DSC curves serve to identify substances, to determine degrees of crystallinity [18] [19] [20] [21].

The heat capacity versus temperature curve is analyzed to determine the transition temperature $\left(T_{m}\right)$, and the calorimetric enthalpy of transition, $\left(\Delta H_{c a l}\right)$. The value of the calorimetric enthalpy $\left(\Delta H_{c a l}\right)$ for the phase transition is determined by integrating the area under the peak.

$$
\Delta H_{c a l}=\int C_{p} \mathrm{~d} T
$$

From these values, the entropy of the phase transition is determined:

$$
\Delta S=\frac{\Delta H_{c a l}}{T_{m}}
$$

The comparison of $\Delta H_{c a b} \Delta S$ and $T_{m}$ shows the effect of structural modification

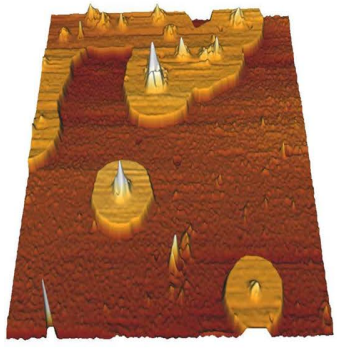

(a)

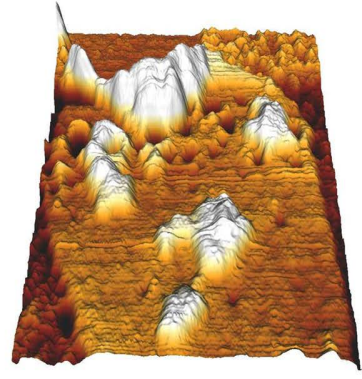

(b)

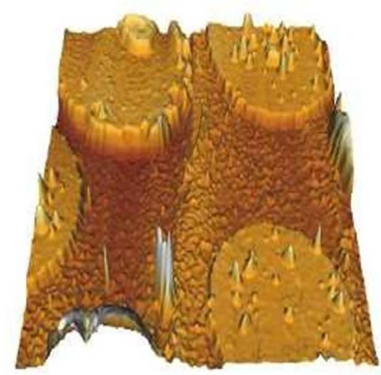

(c)

Figure 3. AFM images by high retrace 3 Dimensiona of monolayer Langmuir-Blodgett films of GDNT, caldarchaeol- $\mathrm{PO}_{4}$, and caldarchaeol-CyCl on the silicon wafer subbtrates. (a) GDNT; (b) Caldarchaeol-PO ; (c) Caldarchaeol-CyCl. 


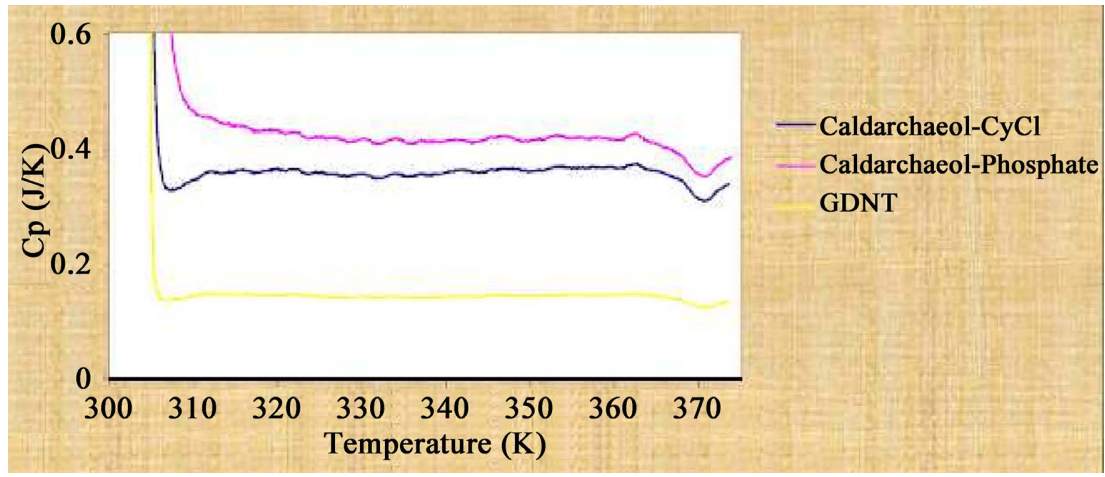

Figure 4. Heat Capacity of Langmuir-Blodgett monolayers of GDNT, caldarchaeol- $\mathrm{PO}_{4}$, and caldarchaeol- $\mathrm{CyCl}$ from temperature $28^{\circ} \mathrm{C}$ to $100^{\circ} \mathrm{C}$ on the wafer silicon substrates [22].

(e.g. chain length) on phase transition thermodynamics.

Bola amphifilics are molecules which have polar head groups and long hydrophobic carbon chains. The monolayers of bolaamphifilic archael tetraether lipids have a spontaneous organizations molecular on the behavior of thermodynamic with the regular structure interactions of hydrogen bond, ionic bonds and Van der Walls bonds. Characterization of Langmuir-Blodgett film of archael tetraether lipids on wafer silicon substrates by DSC obtained the result of tetraether lipids head capacity from a temperature of $28^{\circ} \mathrm{C}$ to $100^{\circ} \mathrm{C}$ as in Figure 4 . The result showed that the variant value of the heat capacity of tetraether lipids. The heat capacity of the asymmetry archael tetraether lipids GDNT has a lower head capacity value than the symmetry of archael tetraether lipids (caldarchaeol- $\mathrm{CyCl}$, caldarchaeol- $\mathrm{PO}_{4}$ ). The ionic bonds in symmetrical archael tetraether lipids (caldarchaeol- $\mathrm{PO}_{4}$, caldarchaeol-CyCl) become the heat capacity of (caldarchaeol- $\mathrm{PO}_{4}$, caldarchaeol-CyCl) are higher than the heat capacity of GDNT which has only hydrogen bonds.

Summarizing our data, we argue that the thermodynamic behavior of organizations molecular membranes of chemical structure modified from the archael tetraether lipids of archebacterium Sulfolobus acidocaldarius on wafer silicon substrates is stable and organized. The thermodynamic stability of biomembranes are is essential for a number of biomedical applications, including intravenous drug delivery, biomaterials, and biosensors.

\section{Acknowledgements}

This study was supported by the Deutscher Akademischer Austauschdienst (DAAD, SV).

\section{Conflicts of Interest}

The authors declare no conflicts of interest regarding the publication of this paper.

\section{References}

[1] Poursoroush, A., Sperotto, M.M. and Laradji, M. (2017) Phase Behavior of Sup- 
ported Lipid Bilayers: A Systematic Study by Coarse-Grained Molecular Dynamics Simulations. The Journal of Chemical Physics, 146, Article ID: 154902. https://doi.org/10.1063/1.4981008

[2] Schuster, B. (2018) S-Layer Protein-Based Biosensors. Biosensors, 8, Article No. 40. https://doi.org/10.3390/bios8020040

[3] Su, Z.F., Leitch, J.J. and Lipkowski, J. (2018) Electrode Supported Biomimetic Membranes An Electrochemical and Surface Science Approach for Characterizing Biological Cell Membranes. Current Opinion in Electrochemistry, 12, 60-72. https://doi.org/10.1016/j.coelec.2018.05.020

[4] Sleytr, U.B., Schuster, B., Egelseer, E.M. and Pum, D. (2014) S-Layers: Principles and Applications. FEMS Microbiology Reviews, 38, 823-864.

https://doi.org/10.1111/1574-6976.12063

[5] Jacobsena, A.C., Jensena, S.M., Frickerc, G., Brandla, M. and Treusch, A.H. (2017) Archaeal Lipids in Oral Delivery of Therapeutic Peptides. European Journal of Pharmaceutical Sciences, 108, 101-110. https://doi.org/10.1016/j.ejps.2016.12.036

[6] Jackman, J.A., Knoll, W. and Cho, N.J. (2012) Biotechnology Applications of Tethered Lipid Bilayer Membranes. Materials, 5, 2637-2657.

https://doi.org/10.3390/ma5122637

[7] Nielsen, C.H. (2009) Biomimetic Membranes for Sensor and Separation Applications. Analytical and Bioanalytical Chemistry, 395, 697-718.

https://doi.org/10.1007/s00216-009-2960-0

[8] Frant, M., Dayyoubb, E., Bakowsky, U. and Liefeitha, K. (2018) Evaluation of a Ureteral Catheter Coating by Means of a BioEncrustation in Vitro Model. International Journal of Pharmaceutics, 546, 86-96. https://doi.org/10.1016/j.ijpharm.2018.04.023

[9] Albers, S.V. and Meyer, B.H. (2011) The Archaeal Cell Envelope. Nature Reviews Microbiology, 9, 414-426. https://doi.org/10.1038/nrmicro2576

[10] Hanford, M.J. and Peeples, T.L. (2002) Archaeal Tetraether Lipids: Unique Structures and Applications. Applied Biochemistry and Biotechnology, 97, 45-62. https://doi.org/10.1385/ABAB:97:1:45

[11] Gliozzi, A., Rolandi, R., De Rosa, M. and Gambacorta, A. (1983) Monolayer Black Membranes from Bipolar Lipids of Archaebacteria and Their Temperature-Induced Structural Changes. The Journal of Membrane Biology, 75, 45-56.

https://doi.org/10.1007/BF01870798

[12] Vidawati, S., Sitterberg, J., Bakowsky, U. and Rothe, U. (2010) AFM and Ellipsometric Studies on LB Films of Natural Asymmetric and Symmetric Bolaamphiphilic Archaebacterial Tetraether Lipids on Silicon Wafers. Colloids and Surfaces B: Biointerfaces, 78, 303-309. https://doi.org/10.1016/j.colsurfb.2010.03.015

[13] Vidawati, S., Sitterberg, J., Rothe, U. and Bakowsky, U. (2011) Stability of Monomolecular Films of Archaebacterial Tetraether Lipids on Silicon Wafers: A Comparison of Physisorbed and Chemisorbed Monolayers. Colloids and Surfaces B: Biointerfaces, 87, 209-216. https://doi.org/10.1016/j.colsurfb.2011.05.005

[14] Vidawati, S., Rothe, U. and Bakowsky, U. (2012) Langmuir Films Stability Phenomenon of Glycerol Dialkyl Nonitol Tetraether at the Air-Water Interface for Variations Spreading Time. Advances in Biological Chemistry, 2, 233-237. https://doi.org/10.4236/abc.2012.23028

[15] Vidawati, S., Bakowsky, U. and Rothe, U. (2020) Stability Behaviour of Monolayer Tetraether Lipids on the Amino-Silanised Silicon Wafer: Comparative Study be- 
tween Langmuir-Blodgett Monolayers with Self-Assembled Monolayers. Advances in Materials Physics and Chemistry, 10, 270-281.

https://doi.org/10.4236/ampc.2020.1011021

[16] Vidawati, S. and Rothe, U. (2015) Monolayers Langmuir-Blodgett Films of Synthetic Artificial Mimic Molecules That Resemble the Following Tetraether Lipids on Silicon Wafers. Advances in Biological Chemistry, 5, 189-196.

https://doi.org/10.4236/abc.2015.54015

[17] Bakowsky, U., Kneuer, C., Rothe, U., Liefeith, K., Frant, M., Dölling, K., Schmid, R., Johnsen, H. and Stenstad, P. (2006) Patent PCT/DE2005/001162.

[18] Pruchnik, H. (2017) Influence of Cytotoxic Butyltin Complexes with 2-Sulfobenzoic Acid on the Thermotropic Phase Behavior of Lipid Model Membranes. Journal of Thermal Analysis and Calorimetry, 127, 507-514.

https://doi.org/10.1007/s10973-016-5489-4

[19] Chiu, M.H. and Prenner, E.J. (2011) Differential Scanning Calorimetry: An Invaluable Tool for a Detailed Thermodynamic Characterization of Macromolecules and Their Interactions. Journal of Pharmacy and Bioallied Sciences, 3, 39-59.

https://doi.org/10.4103/0975-7406.76463

[20] Aburahma, M.H. and Badreldin, S.M. (2014) Compritol 888 ATO: A Multifunctional Lipid Excipient in Drug Delivery Systems and Nanopharmaceutical. Expert Opinion on Drug Delivery, 11, 1865-1883.

https://doi.org/10.1517/17425247.2014.935335

[21] Freisleben, H.J. (2019) The Main (Glyco) Phospholipid (MPL) of Thermoplasma acidophilum. International Journal of Molecular Sciences, 20, Article No. 5217. https://doi.org/10.3390/ijms20205217

[22] Vidawati, S. (2012) Organization Monomolecular of Archaeal Tetraether Lipids on the Silicon Wafers Prepared by Langmuir-Blodgett Method. OmniScriptum GmbH \& Co. KG (LAP LAMBERT Academic Publishing). 